Case Report

\title{
Mild Clinical Course of Severe Fever with Thrombocytopenia Syndrome Virus Infection in an Elderly Japanese Patient
}

\author{
Yuko Ohagi, ${ }^{1}$ Shinobu Tamura, ${ }^{2}$ Chiaki Nakamoto, ${ }^{3}$ Hiromichi Nakamoto, ${ }^{4}$ \\ Masayuki Saijo, ${ }^{5}$ Masayuki Shimojima, ${ }^{5}$ Yoshio Nakano, ${ }^{1}$ and Tokuzo Fujimoto ${ }^{1}$ \\ ${ }^{1}$ Department of Internal Medicine, Kinan Hospital, 46-70 Shinjo, Tanabe-shi, Wakayama 646-8588, Japan \\ ${ }^{2}$ Department of Hematology/Oncology, Kinan Hospital, 46-70 Shinjo, Tanabe-shi, Wakayama 646-8588, Japan \\ ${ }^{3}$ Department of Nursing, Kinan Hospital, 46-70 Shinjo, Tanabe-shi, Wakayama 646-8588, Japan \\ ${ }^{4}$ Department of Central Clinical Laboratory, Kinan Hospital, 46-70 Shinjo, Tanabe-shi, Wakayama 646-8588, Japan \\ ${ }^{5}$ Special Pathogens Laboratory, Department of Virology 1, National Institute of Infectious Diseases, 4-7-1 Gakuen, \\ Musashimurayama, Tokyo 208-0011, Japan \\ Correspondence should be addressed to Shinobu Tamura; stamura@kinan-hp.tanabe.wakayama.jp
}

Received 1 September 2014; Revised 18 November 2014; Accepted 18 November 2014; Published 7 December 2014

Academic Editor: Gernot Walder

Copyright (C) 2014 Yuko Ohagi et al. This is an open access article distributed under the Creative Commons Attribution License, which permits unrestricted use, distribution, and reproduction in any medium, provided the original work is properly cited.

Severe fever with thrombocytopenia syndrome (SFTS) is an emerging infectious and hemorrhagic disease recently described in China and western Japan. A 71-year-old healthy Japanese woman noticed a tick biting her after harvesting in an orchard and removed it herself. She developed diarrhea, anorexia, and chills eight days later. Because these symptoms continued, she visited a primary care physician 6 days after the onset. Laboratory data revealed thrombocytopenia, leukocytopenia, and elevated liver enzymes. She was then referred to our hospital. Although not completely fulfilling the diagnostic criteria used in a retrospective study in Japan, SFTS was suspected, and we detected SFTS virus in the patient's blood using RT-PCR. However, she recovered without intensive treatment and severe complications 13 days after the onset. In this report, we present a mild clinical course of SFTS virus infection in Japan in detail.

\section{Introduction}

An outbreak of an unknown infectious disease characterized by high fever, gastrointestinal symptoms, thrombocytopenia, and leukocytopenia occurred between March and July 2009 in China, with a high fatality rate (30\%). The emerging infectious disease was named severe fever with thrombocytopenia syndrome (SFTS) based on its clinical characteristics. In 2011, Yu et al. identified a tick-borne infectious disease caused by the SFTS virus (SFTSV), a Phlebovirus from the Bunyaviridae family [1]. In Japan, a female patient who lived in the Yamaguchi prefecture was the first to be diagnosed with SFTS in Japan in 2012, and she eventually died due to multiple organ failure (MOF) [2]. The study was retrospectively performed in Japan between 2005 and 2012 and included ten additional patients newly diagnosed with SFTS. All SFTS patients were aged over 50 years and lived in western Japan. Six of these patients eventually died, resulting in a higher fatality rate than that in China [2]. Until June 2014, 67 patients in Japan had been diagnosed with SFTS, and 22 had fatal outcomes. This emerging infectious disease has been gradually introduced to the Japanese population. A recent Infectious Agents Surveillance Report published by the National Institute of Infectious Disease (NIID) stated that a SFTS case not meeting all diagnostic criteria would have a good outcome [3]. Here we report a case of an elderly Japanese patient with a mild clinical course of SFTS in the easternmost region of Japan.

\section{Case Presentation}

In early June, a 71-year-old previously healthy woman, who engaged in agricultural activities in a hilly rural area, noticed a tick biting her left thigh while bathing after harvesting in an 
TABLE 1: Clinical course of hemoglobin, leukocyte and platelet counts, AST, ALT, creatine kinase, LDH, aPTT, prothrombin time, and Creactive protein after the onset of SFTS.

\begin{tabular}{|c|c|c|c|c|c|c|}
\hline Laboratory test (reference range) & Day 4 & Day 7 & Day 8 & Day 9 & Day 10 & Day 13 \\
\hline Hemoglobin, g/dL (11.5-15.3) & 14.4 & 16.4 & 13.2 & 12.3 & 13.1 & 12.7 \\
\hline Leukocyte, $\times 10^{3} / \mu \mathrm{L}(4-9.5)$ & 3.0 & 4.9 & 3.9 & 4.2 & 4.2 & 4.4 \\
\hline Neutrophil, \% (39-73) & NA & 45 & 32 & 61 & 56 & 59 \\
\hline Lymphocyte, \% (19-50) & NA & 36 & 52 & 29 & 35 & 27 \\
\hline Atypical lymphocyte, \% (0) & NA & 15 & 3 & 0 & 0 & 0 \\
\hline Erythroblast, cell/100 WBC (0) & NA & 1 & 0 & 0 & 0 & 0 \\
\hline Platelet, $\times 10^{3} / \mu \mathrm{L}(150-400)$ & 61 & 73 & 79 & 89 & 241 & 431 \\
\hline AST, IU/L (11-35) & 157 & 267 & 192 & 147 & 86 & 42 \\
\hline ALT, IU/L (5-35) & 66 & 122 & 97 & 89 & 82 & 56 \\
\hline Creatine kinase, IU/L (45-235) & 155 & 207 & 127 & 86 & 52 & 31 \\
\hline LDH, IU/L (120-230) & 483 & 577 & 437 & 356 & 284 & 206 \\
\hline aPTT, sec (20-35) & NA & 33.8 & 31.3 & 30.5 & 29.3 & 26.9 \\
\hline Prothrombin time, INR (0.8-1.2) & NA & 0.88 & 0.89 & 0.92 & 0.98 & 1.03 \\
\hline C-reactive protein, $\mathrm{mg} / \mathrm{dL}(0-0.5)$ & 1.10 & 0.23 & 0.15 & 0.26 & 0.29 & 0.04 \\
\hline
\end{tabular}

* Day 1 was onset day. NA: not available; WBC: white blood cell; AST: aspartate aminotransferase; ALT: alanine aminotransferase; LDH: lactate dehydrogenase; aPTT: activated partial prothromboplastin time; INR: international normalized ratio.

orchard. The species of the tick remains unclear. She properly removed the head of the tick herself. However, she suddenly developed watery diarrhea (4-5 times a day), anorexia, and left inguinal lymphadenopathy eight days later. She also felt cold but did not measure her body temperature. Because these symptoms did not improve, particularly her gastrointestinal symptoms, she visited a primary care physician 4 days after the onset of the illness. Laboratory data revealed low platelet and white blood cell counts as well as elevated liver enzymes (Table 1). Although the watery diarrhea and chills gradually improved, she was admitted to our hospital seven days after the onset of the illness due to anorexia.

On admission, the patient had a slight headache, but no fever or neurological symptoms. A left inguinal lymph node was swollen, but indolent, whereas none of the other superficial lymph nodes or tonsils were enlarged. The patient did not exhibit erythema, wheal, or petechial rash. A small tick bite was observed in the lateral aspect of her left thigh (Figure 1(a)). Laboratory tests on admission also showed a low platelet count of $7.3 \times 10^{4} / \mu \mathrm{L}$. Coagulation data did not fulfill the diagnostic criteria of disseminated intravascular coagulation (DIC) [4]. White blood cell count was 4.9 $\times 10^{3} / \mu \mathrm{L}$, which was within the normal range; however, $15 \%$ were atypical lymphocytes. Serum levels of alanine aminotransferase (ALT; $267 \mathrm{IU} / \mathrm{L}$ ), aspartate aminotransferase (AST; $122 \mathrm{IU} / \mathrm{L}$ ), and lactate dehydrogenase (LDH; 577 IU/L) were high, whereas creatine kinase (CK), alkaline phosphatase, $\gamma$-glutamyl transpeptidase, and C-reactive protein (CRP) levels were nearly within normal ranges (Tables 1 and 2). Bone marrow aspiration revealed a mild hypocellular marrow with platelet-specific hemophagocytosis (Figure 1(b)). Contrast-enhanced computed tomography showed significant left inguinal lymphadenopathy (Figure 1(c)). After a few days, serological results confirmed that this disease was not an acute infection by EpsteinBarr virus, cytomegalovirus, or scrub typhus. Although her clinical course did not fulfill the full diagnostic criteria for SFTS, which were previously used in a retrospective study [2], we suspected SFTS and sent her peripheral blood on admission to NIID. The patient had mild hypovolemia in the absence of electrolyte imbalance, and replacement therapy with an adequate infusion fluid was initiated. Minocycline (200 mg/day) was administered intravenously because Rickettsia tsutsugamushi was also included in the differential diagnosis. On the 5 th day of her admission, serum IgM antibodies to SFTSV were detected by enzyme-linked immunosorbent assay (ELISA), and the SFTSV nucleoprotein (NP) gene was detected by conventional one-step reverse-transcription polymerase chain reaction (RT-PCR; Figure 2 ). In addition, the level of the SFTSV genome in her blood was $10^{4.86}$ copies/mL, as determined using quantitative RT-PCR. These results supported the definitive diagnosis of SFTSV infection. We submitted a notification of the occurrence of this infectious disease to the public health center. The administration of minocycline was discontinued after the definitive diagnosis. Platelet count became markedly elevated 10 days after the onset of the illness (Table 1). Serum transaminases returned to almost normal levels 13 days after the onset (Table 1). Her anorexia also simultaneously recovered, and she was subsequently discharged. She never developed fever during her hospitalization.

\section{Discussion}

In a retrospective study performed in Japan, SFTS was defined as a case in which all of the following seven requirements were met: (1) fever of $38^{\circ} \mathrm{C}$ or higher, (2) digestive symptoms, (3) thrombocytopenia, (4) leukocytopenia, (5) elevated AST/ALT/LDH levels, (6) no other clear cause, and (7) intensive care required or death [2]. The degree of fever in the present case remained unclear before her admission, and she did not require intensive care throughout 


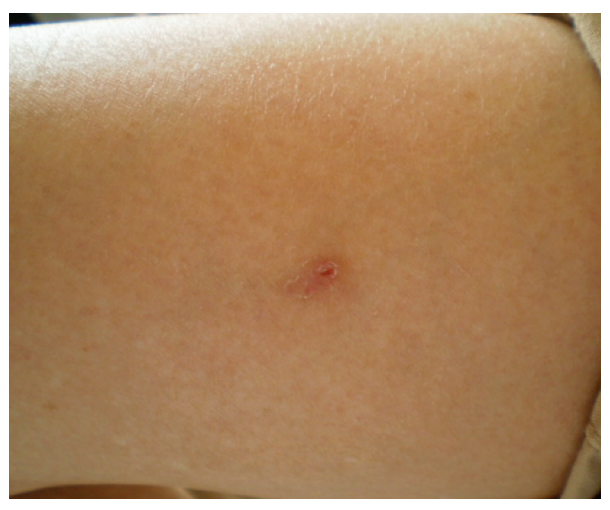

(a)

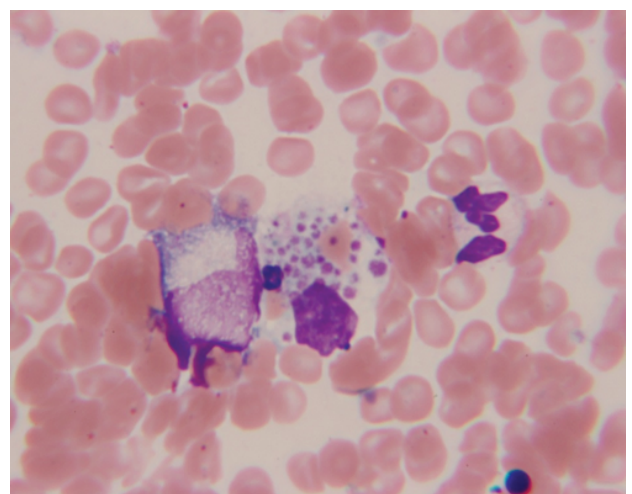

(b)

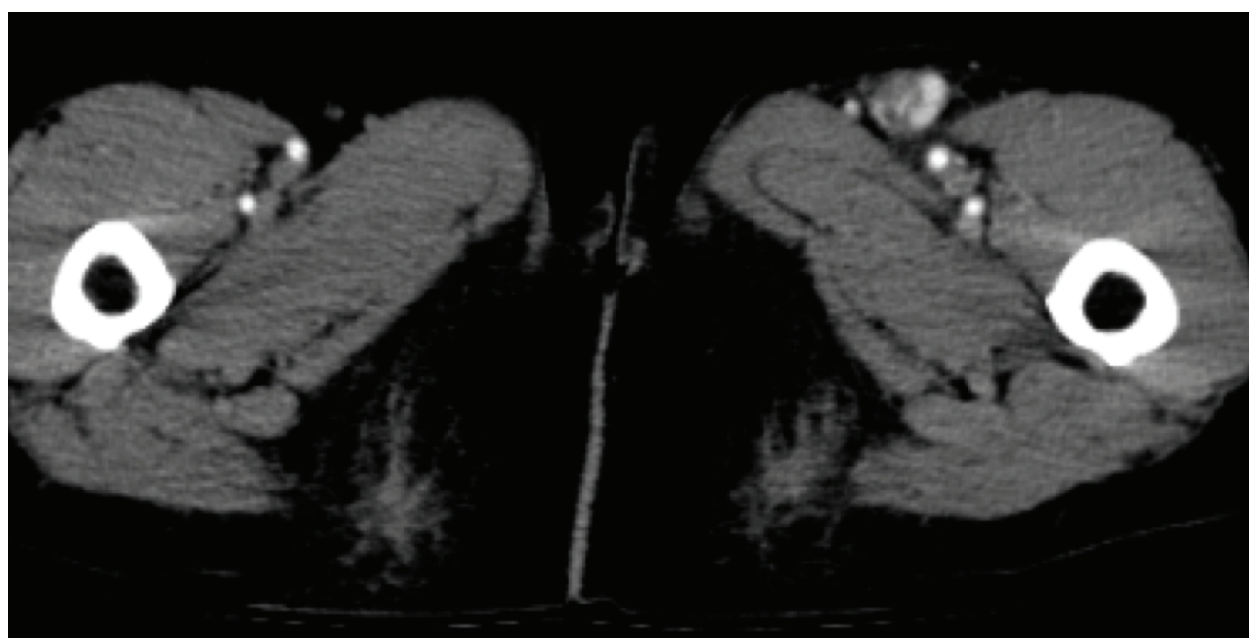

(c)

FIGURE 1: Clinical signs of an elderly patient with SFTSV infection. (a) A tick bite was found on the left thigh. (b) Microscopic findings of Giemsa staining of bone marrow showed platelet-specific hemophagocytes. (c) Contrast-enhanced computed tomography showed left inguinal lymphadenopathy alone.

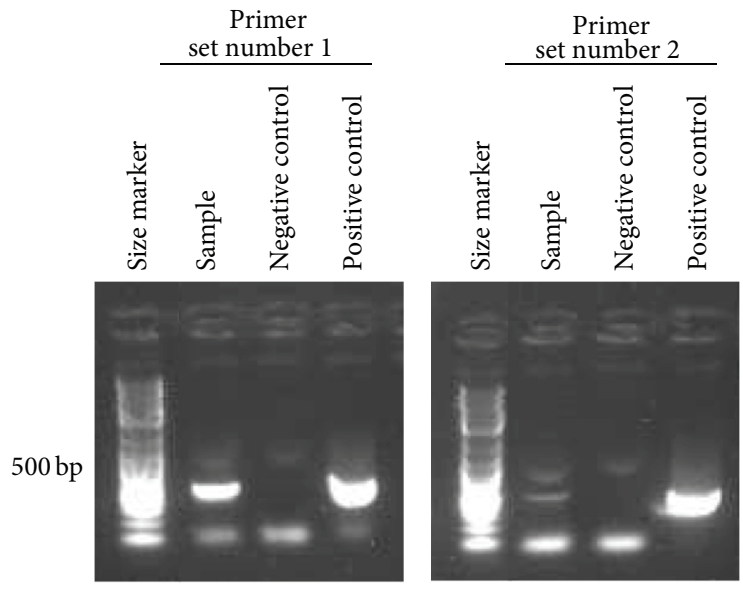

FIGURE 2: Detection of Japanese SFTSV mRNA using a conventional one-step RT-PCR method. Clinical specimen by RT-PCR: lane 1: our patient's blood sample; lane 2: negative control (NTC); lane 3: positive control (PC) (SFTSV strain HB29 viral RNA). Primer sets numbers 1 and 2 amplified the gene coding SFTSV NP, and the sizes of these products were $458 \mathrm{bp}$ and $461 \mathrm{bp}$, respectively. the clinical course. Although this did not reflect typical SFTS, clinical characteristics such as hemophagocytosis and unilateral lymphadenopathy were consistent with SFTS [1, $2,5,6]$. Therefore, we performed tests to identify SFTSV. A definitive diagnosis was ultimately reached on the 5th day after admission (12th day from the onset), when her serum samples were found to be positive for IgM antibodies to SFTSV, and the SFTSV NP gene was detected.

In the initial medical examination, it was difficult to distinguish the present case from a Rickettsia infection, which is relatively common in this area; therefore, we continued to administer tetracycline antibiotics until a definitive diagnosis could be reached. Because no curative treatment is currently present for SFTS, symptomatic and supportive therapies are typically performed, with systemic antibiotics being used to treat secondary infections [5]. In this present case, we accordingly administered symptomatic and supportive treatments after reaching a definitive diagnosis of SFTS. Throughout the entire course, the patient did not require intensive care, and her symptoms improved with fluid replacement for dehydration alone, suggesting that she had a mild clinical 
TABLE 2: Laboratory data of a Japanese elderly patient with mild SFTS on the admission.

\begin{tabular}{|c|c|}
\hline \multicolumn{2}{|l|}{ Complete blood count } \\
\hline White blood cell & $4,900 / \mu \mathrm{L}$ \\
\hline Neutrophil & $45.0 \%$ \\
\hline Lymphocyte & $36.0 \%$ \\
\hline Monocyte & $4.0 \%$ \\
\hline Eosinophil & $0.0 \%$ \\
\hline Basophil & $0.0 \%$ \\
\hline Atypical lym. & $15.0 \%$ \\
\hline Erythroblast & 1 cell/100 WBC \\
\hline Red blood cell & $561 \times 10^{4} / \mu \mathrm{L}$ \\
\hline Hemoglobin & $16.4 \mathrm{~g} / \mathrm{dL}$ \\
\hline Hematocrit & $47.7 \%$ \\
\hline Platelet & $7.3 \times 10^{4} / \mu \mathrm{L}$ \\
\hline \multicolumn{2}{|l|}{ Coagulation system } \\
\hline aPTT & $33.8 \mathrm{sec}$ \\
\hline PT (\%) & $166 \%$ \\
\hline PT-INR & 0.88 \\
\hline Fibrinogen & $246 \mathrm{mg} / \mathrm{dL}$ \\
\hline FDP & $4.34 \mu \mathrm{g} / \mathrm{mL}$ \\
\hline \multicolumn{2}{|l|}{ Chemistry } \\
\hline Creatinine & $0.90 \mathrm{mg} / \mathrm{dL}$ \\
\hline BUN & $22.0 \mathrm{mg} / \mathrm{dL}$ \\
\hline Sodium & $136 \mathrm{mEq} / \mathrm{L}$ \\
\hline Potassium & $3.9 \mathrm{mEq} / \mathrm{L}$ \\
\hline Chloride & $97 \mathrm{mEq} / \mathrm{L}$ \\
\hline AST & $267 \mathrm{IU} / \mathrm{L}$ \\
\hline ALT & $122 \mathrm{IU} / \mathrm{L}$ \\
\hline ALP & $202 \mathrm{IU} / \mathrm{L}$ \\
\hline$\gamma$-GTP & $52 \mathrm{IU} / \mathrm{L}$ \\
\hline T-Bil & $0.5 \mathrm{mg} / \mathrm{dL}$ \\
\hline $\mathrm{LDH}$ & $577 \mathrm{IU} / \mathrm{L}$ \\
\hline Creatine Kinase & $207 \mathrm{IU} / \mathrm{L}$ \\
\hline Total Protein & $6.2 \mathrm{~g} / \mathrm{dL}$ \\
\hline Albumin & $3.5 \mathrm{~g} / \mathrm{dL}$ \\
\hline CRP & $0.23 \mathrm{mg} / \mathrm{dL}$ \\
\hline Glucose & $196 \mathrm{mg} / \mathrm{dL}$ \\
\hline Endotoxin & $<2 \mathrm{pg} / \mathrm{mL}$ \\
\hline Procalcitonin & 0.207 \\
\hline Ferritin & $1713 \mathrm{ng} / \mathrm{mL}$ \\
\hline Soluble IL-2R & $1235 \mathrm{U} / \mathrm{mL}$ \\
\hline HbAlc & $5.7 \%$ \\
\hline $\operatorname{IgG}$ & $1035 \mathrm{mg} / \mathrm{dL}$ \\
\hline $\operatorname{Ig} \mathrm{A}$ & $129 \mathrm{mg} / \mathrm{dL}$ \\
\hline $\operatorname{IgM}$ & $34 \mathrm{mg} / \mathrm{dL}$ \\
\hline Anti-nuclear antibody & $<40$ \\
\hline HBs antigen & $(-)$ \\
\hline $\mathrm{HCV}$ antibody & $(-)$ \\
\hline HIV antibody & $(-)$ \\
\hline ТРНА & $(-)$ \\
\hline \multicolumn{2}{|l|}{ Urea } \\
\hline & $>1.030$ \\
\hline
\end{tabular}

TABle 2: Continued.

\begin{tabular}{lc}
\hline $\mathrm{pH}$ & 6.5 \\
Protein & $(2+)$ \\
Sugar & $(-)$ \\
Ketone & $(-)$ \\
Occult blood & $(1+)$ \\
\hline
\end{tabular}

Lym.: lymphocyte; WBC: white blood cells; PT: prothrombin time; FDP: fibrin/fibrinogen degradation products; BUN: blood urea nitrogen; ALP: alkaline phosphatase; $\gamma$-GTP: $\gamma$-glutamyltransferase; T-Bil: total bilirubin; CRP: C-reactive protein; IL-2R: interleukin-2 receptor; Ig: immunoglobulin; HBs: hepatitis B surface; HCV: hepatitis C virus; HIV: human immunodeficiency virus; TPHA: treponema pallidum latex agglutination.

course of SFTS. In China, previous studies have shown that administration of ribavirin, an antiviral drug, against a broad range of RNA viruses, could successfully treat some SFTS patients; however, this treatment is currently not considered to be effective [5-8].

The clinical course of SFTS has largely been divided into 4 stages: (1) incubation, (2) fever stage, (3) MOF stage, and (4) convalescence [5]. After the tick bite, the incubation period lasts for 5 to 14 days. The disease then presents with flu-like symptoms such as fever, headache, malaise, muscular pain, and diarrhea $[1,2,5,6]$. Most patients generally shift into the MOF stage after a fever stage of 5 to 11 days. Physicians are required to exercise extreme caution here because the most severe leukocytopenia and thrombocytopenia have been reported in the MOF stage; both MOF and DIC have been common, causing several fatalities $[1,2,5,6]$. The present patient was hospitalized 7 days after the onset of the illness and exhibited no fever. These results suggested that she had passed the fever stage and may already have been in the MOF stage. Prognostic factors for SFTS include abnormal levels of AST, LDH, CK, and CK-MB; abnormal neurological findings; bleeding; DIC; and MOF [6]. Our patient did not exhibit any of these factors, thereby supporting a better outcome on admission.

The viral load of SFTSV in peripheral blood decreases slightly in survivors with the infection, whereas a high titer level of $10^{8}$ copies $/ \mathrm{mL}$ or more leads to fatal outcomes [5, 9]. Previous studies reported that the mortality risk was higher for cases with a viral load of $10^{5}$ copies $/ \mathrm{mL}$ or more in peripheral blood after symptom onset [5,9]. The viral load in the present case was not periodically measured over time, and it was impossible to accurately compare the viral load reported in China with that of this case because of sequence mismatches between the Chinese and Japanese SFTSV lineages [9]. In Japan, Yoshikawa et al. developed a conventional and quantitative one-step RT-PCR capable of detecting Japanese SFTSV and recently reported that viral loads of less than $10^{5}$ copies $/ \mathrm{mL}$, as found in the present study, were lower than the mean level measured in the survivor group, which is consistent with previous findings reported by Zhang et al. $[9,10]$. Thus, the relatively low viral SFTV load in the blood sample of our patient on admission also contributed to her mild clinical course.

As of June 2014, SFTS has been confirmed in areas to the west of our hospital (particularly in the Kyushu and Shikoku 
regions) $[2,11]$. Ticks carrying SFTSV and animals positive for SFTSV antibodies have been detected in various areas in the absence of human SFTS cases [11]. In the Wakayama prefecture, where our hospital is located, the present case is the first report of SFTSV infection developing in the easternmost area of Japan when the disease was diagnosed. Outbreaks of SFTS in China from 2009 onwards have been most common between May and August [1, 5, 12-14]. On the other hand, outbreaks in the Kyushu region were found to be relatively common in the fall and winter in addition to the period between May and August [2,11]. These findings suggest that future SFTS outbreaks may occur in more eastern regions throughout the entire year. Physicians in Japan should also pay special attention to the diagnosis of SFTS.

Several cases of severe SFTS were reported between 2011 and 2012 in the Xinyang region in China [12]. Most cases were of elderly farmers in the southern and western areas of this region. Furthermore, high-risk areas of SFTSV infection include environments such as shrubs, forests, and rain-fed croplands [12]. SFTS in Japan appears to be characterized by a spread from western to eastern Japan. A detailed study of high-risk areas for SFTS, similar to that in the Xinyang region in China, should be conducted in Japan. Our patient was also an elderly farmer working in an orchard, which represents an environment where SFTS has commonly occurred in China. Thus, orchards appear to be high-risk areas for SFTSV infection and are now being monitored for this infectious disease. Person-to-person transmission by bloodstream infections, which was reported in China, was not observed in the present case $[15,16]$. Standard precautions were strictly followed during the patient's hospitalization.

Here we described a patient with a mild clinical course of SFTSV infection in the easternmost area of Japan. Mild cases may not be diagnosed in routine clinical practice and thus may be overlooked. Therefore, the incidence of SFTSV infection may be higher than reported. Early diagnosis, effective treatment, and prevention need to be established to prevent future endemic spread of SFTSV infection.

\section{Conflict of Interests}

The authors declare that they have no conflict of interests.

\section{References}

[1] X.-J. Yu, M.-F. Liang, S.-Y. Zhang et al., "Fever with thrombocytopenia associated with a novel bunyavirus in China," The New England Journal of Medicine, vol. 364, no. 16, pp. 1523-1532, 2011.

[2] T. Takahashi, K. Maeda, T. Suzuki et al., "The first identification and retrospective study of Severe Fever with Thrombocytopenia Syndrome in Japan," Journal of Infection Disease, vol. 209, no. 6, pp. 816-827, 2014.

[3] K. Izukawa, T. Miyamura, S. Hara et al., "Mild SFTS case whose clinical differential diagnosis from rickettsiosis was difficult, April 2013," Infectious Agents Surveillance Report, vol. 35, p. 39, 2013.

[4] T. Kaneko and H. Wada, "Diagnostic criteria and laboratory tests for disseminated intravascular coagulation," Journal of
Clinical and Experimental Hematopathology, vol. 51, no. 2, pp. 67-76, 2011.

[5] Q. Liu, B. He, S.-Y. Huang, F. Wei, and X.-Q. Zhu, "Severe fever with thrombocytopenia syndrome, an emerging tickborne zoonosis," The Lancet Infectious Diseases, vol. 14, no. 8, pp. 763-772, 2014.

[6] Z.-T. Gai, Y. Zhang, M.-F. Liang et al., "Clinical progress and risk factors for death in severe fever with thrombocytopenia syndrome patients," The Journal of Infectious Diseases, vol. 206, no. 7, pp. 1095-1102, 2012.

[7] W. Liu, Q.-B. Lu, N. Cui et al., "Case-Fatality ratio and effectiveness of ribavirin therapy among hospitalized patients in china who had severe fever with thrombocytopenia syndrome," Clinical Infectious Diseases, vol. 57, no. 9, pp. 1292-1299, 2013.

[8] W. S. Oh, S. T. Heo, S. H. Kim, W. J. Choi, M. G. Han, and J. Y. Kim, "Plasma exchange and ribavirin for rapidly progressive severe fever with thrombocytopenia syndrome," International Journal of Infectious Diseases, vol. 18, no. 1, pp. 84-86, 2014.

[9] Y.-Z. Zhang, Y.-W. He, Y.-A. Dai et al., "Hemorrhagic fever caused by a novel Bunyavirus in china: pathogenesis and correlates of fatal outcome," Clinical Infectious Diseases, vol. 54, no. 4, pp. 527-533, 2012.

[10] T. Yoshikawa, S. Fukushi, H. Tani et al., "Sensitive and specific PCR systems for the detection of both Chinese and Japanese severe fever with thrombocytopenia syndrome virus strains, and the prediction of the patient survival based on the viral load," Journal of Clinical Microbiology, vol. 52, no. 9, pp. 33253333, 2014.

[11] T. Kishimoto and K. Kida, "Diagnosis, treatment and prevention of infectious diseases. Topics: I. Countermeasures against epidemic infectious diseases; 7. Recent tick-borne diseaseSFTS (severe fever with thrombocytopenia syndrome)," Nihon Naika Gakkai Zasshi, vol. 102, no. 11, pp. 2846-2853, 2013.

[12] K. Liu, N. Cui, L.-Q. Fang et al., "Epidemiologic features and environmental risk factors of severe fever with thrombocytopenia syndrome, Xinyang, China," PLoS Neglected Tropical Diseases, vol. 8, no. 5, Article ID e2820, 2014.

[13] H.-L. Wen, L. Zhao, S. Zhai et al., "Severe fever with thrombocytopenia syndrome, Shandong Province, China, 2011," Emerging Infectious Diseases, vol. 20, no. 1, pp. 1-5, 2014.

[14] J. Sun, C. Chai, H. Lv et al., "Epidemiological characteristics of severe fever with thrombocytopenia syndrome in Zhejiang Province, China," International Journal of Infectious Disease, vol. 25, pp. 180-185, 2014.

[15] C.-J. Bao, X.-L. Guo, X. Qi et al., "A family cluster of infections by a newly recognized bunyavirus in Eastern China, 2007: further evidence of person-to-person transmission," Clinical Infectious Diseases, vol. 53, no. 12, pp. 1208-1214, 2011.

[16] Y. Wang, B. Deng, J. Zhang, W. Cui, W. Yao, and P. Liu, "Person-to-person asymptomatic infection of severe fever with thrombocytopenia syndrome virus through blood contact," Internal Medicine, vol. 53, no. 8, pp. 903-906, 2014. 


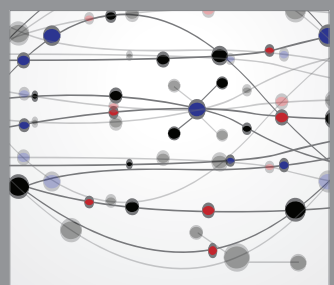

The Scientific World Journal
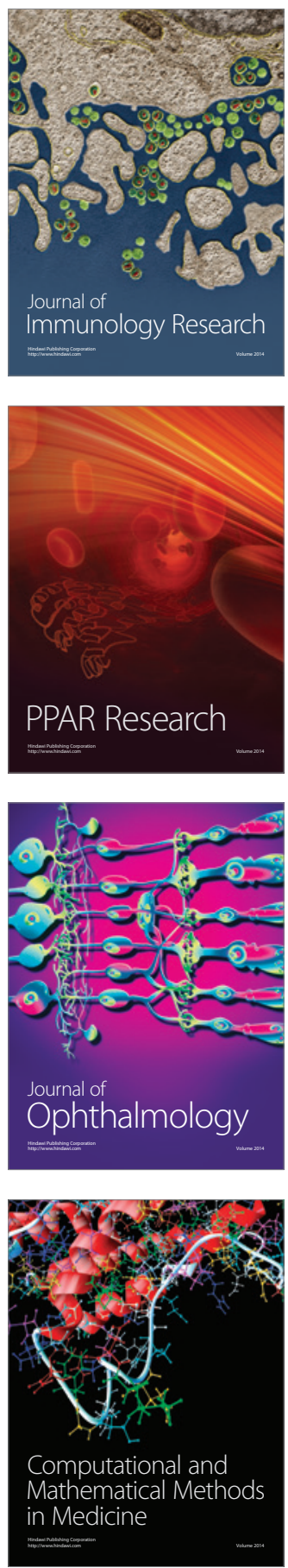

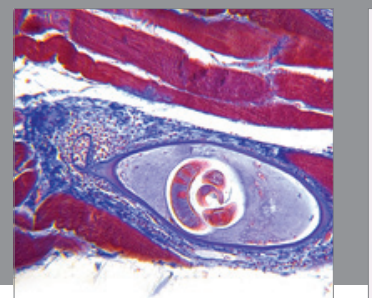

Gastroenterology

Research and Practice
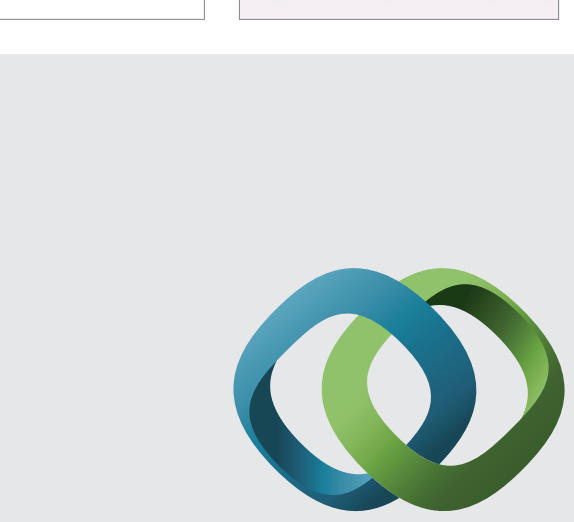

\section{Hindawi}

Submit your manuscripts at

http://www.hindawi.com
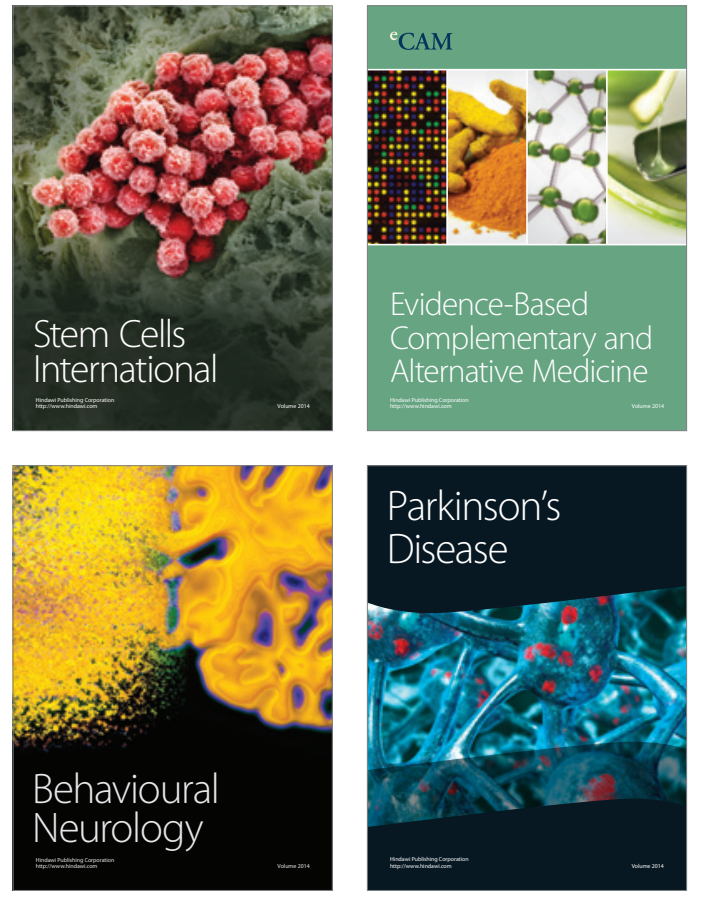
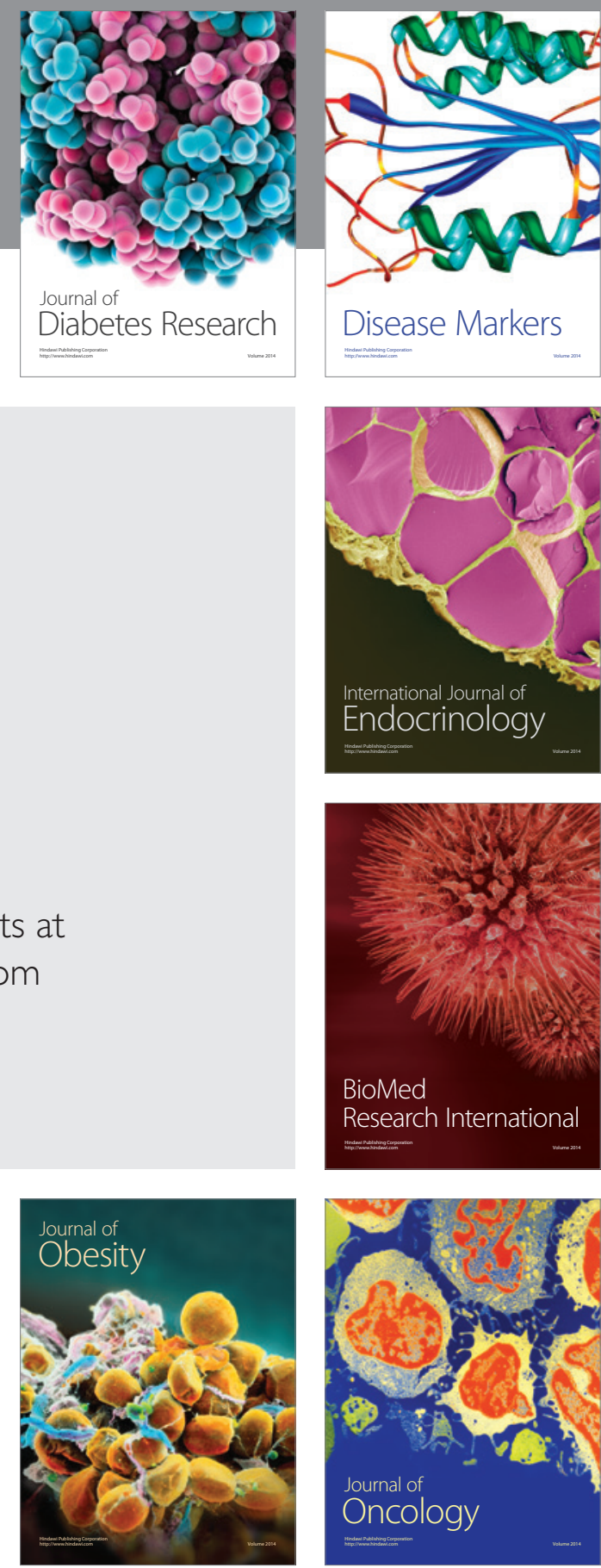

Disease Markers
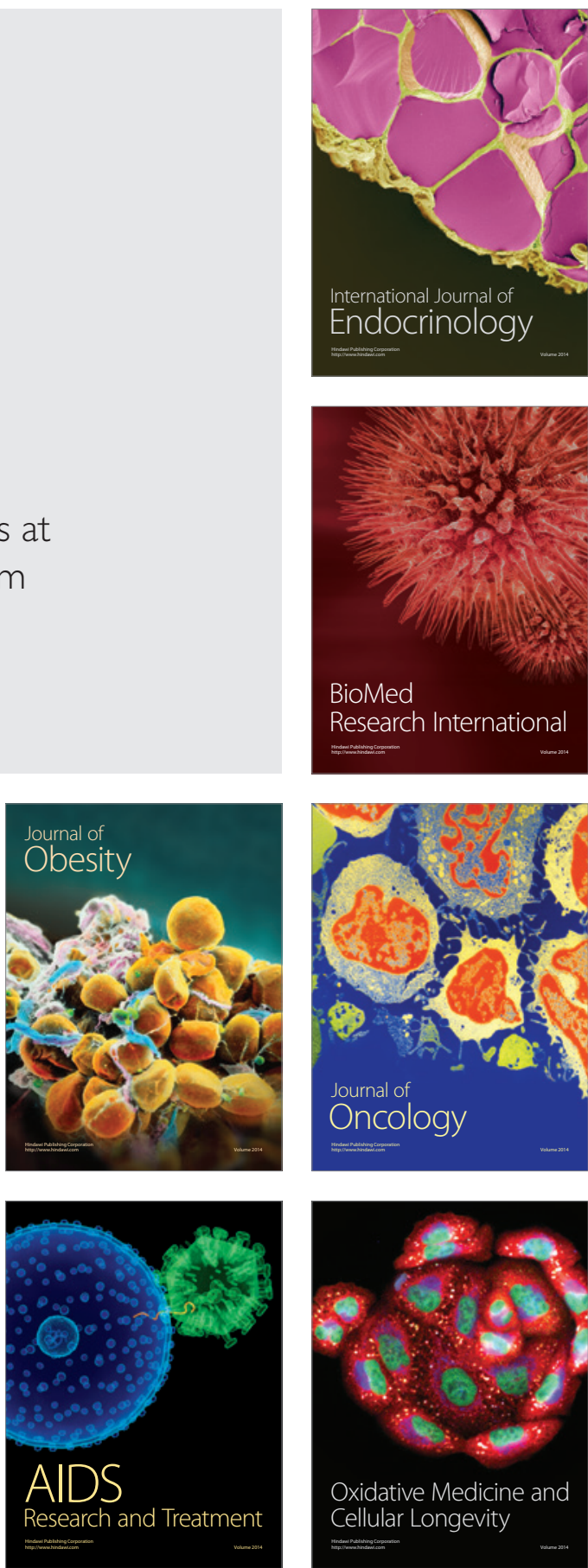